\title{
Notas al comentario de H. Schettino
}

\author{
Antonella Attili
}

L

os señalamientos críticos que Humberto Schettino dirige al artículo "Derecho y poder en la crisis de la soberanía"* apuntan a aspectos diversos que encuentra necesitados de esclarecimiento y precisión. A ellos intentaré responder siguiendo el orden propuesto por su comentario, no sin antes agradecerle el mismo.

En las consideraciones iniciales, Schettino se refiere a la soberanía como la "capacidad de establecer y ejercer poder"; la afirmación sugiere que esté hablando de la idea de potencia (capacidad, Macht), impresión confirmada por la mención de la oposición soberanía-anarquía. Sin duda la capacidad de establecer y ejercer poder es una condición necesaria para la existencia y mantenimiento de lo que se define como poder político, pero la soberanía es algo más que eso: es el reconocimiento jurídico político del poder, específicamente del Estado moderno, y no la mera capacidad de mandar o ejercer poder. Usando la relación de oposiciones sugerida por el comentarista podríamos decir que "soberanía" no es el término correcto a oponer a "anarquía" - como hace en su comentario-, sino más bien "orden"; la soberanía por su parte, en tanto reconocimiento jurídico y político es relativa a la formalización y fundamentación sucesiva del poder político supremo del Estado moderno.

Al reducir el significado de soberanía a la capacidad de poder se entiende la mención que encontramos enseguida de una relación genérica entre soberanía y civilización. Ésta parece desviante (mucho antes de la soberanía hubo civilización/es), ya que atribuye la soberanía analizada a todo poder político en cuanto tal. Pero la soberanía es algo más que concentración de poder en

*Antonella Atilli, "Derecho y poder en la crisis de la soberanía", en Theoría. Revista del Colegio de Filosofía, núm. 7, diciembre, 1998. 
una unidad de mando centralizada; es específicamente la noción jurídico política vinculada al surgimiento de un particular tipo de poder, el del Estado moderno; es la noción jurídica y política relativa al reconocimiento y fundamentación del poder político en la modernidad (en este sentido no sólo orden ni mera capacidad de poder). Quizás sea esta igualación de soberanía con orden lo que explique que Schettino entienda: 1) la paradoja de la soberanía como relacionada a la limitación liberal (principalmente liberal, aunque acompañada en esta tarea de limitación por las otras tradiciones referidas) y 2) la defensa de la que más abajo define como el argumento central en el ataque liberal a la soberanía absoluta.

Con respecto a la referencia del comentarista a la "paradoja de la soberanía (primer nivel)" hay que precisar que ésta no atañe a su limitación liberal, ya que entre las diferentes concepciones válidas de soberanía se encuentra la de soberanía limitada. La paradoja se plantea más bien con relación a la aparente contradicción causada por la presencia en la noción vigente de soberanía de los resabios de significados asumidos con las tradiciones modernas y los significados contemporáneos impuestos por la nueva realidad a la soberanía.

El objetivo de "Derecho y poder en la crisis de la soberanía" no es reconstruir analíticamente las "diferentes versiones de la soberanía", por lo que la insatisfacción de Schettino ante la referencia a diversas tradiciones de pensamiento político se debe a que ahí interesaba analizar específicamente la relación entre poder y derecho en esas posturas, con la finalidad de ubicar y comprender la mezcla de elementos muy diversos que constituyen el significado complejo de "soberanía" y que la hacen una noción de no tan fácil eliminación o sustitución, al no poseer un significado unívoco ni unívocamente aceptable o inaceptable.

Las inquietudes de Humberto Schettino acerca de lo que sería el "conflicto fundamental de la oposición entre soberanía absoluta y limitada" y de la falta de "claridad necesaria (para con) los objetivos de la crítica liberal a la soberanía absoluta” pueden ser respondidas como sigue. Según el comentarista esta soberanía "no tendría como objeto la ausencia de límites al ejercicio del poder ni la arbitrariedad del mismo (límites de facto)"; si bien existían de hecho límites a la soberanía, éstos no impidieron la construcción, afirmación y persistencia de la soberanía absoluta. Pero sobre todo se trata de una noción jurídica y política cuya construcción formal y articulación histórica van más allá de los eventuales condicionamientos fácticos. Es decir, que, aunque la soberanía absoluta puede no haber sido nunca efectiva y realmente absoluta en este mundo, ello no obstó para que la formulación teórico-jurídica y política haya elaborado tales significados.

Por ello no parece que el argumento de los límites de facto pueda ser válido para afirmar que la postura liberal no haya estado dirigida contra la 
ausencia de límites al poder arbitrario. Sin duda "lo inaceptable para Locke era la concentración del poder", pero no porque fuera el fin u objeto de su lucha teórico-política sino por ser el medio necesario para la misma. La oposición de Locke a la concentración del poder justo se debe al problema que le preocupaba: el abuso de poder por parte del poder político, sin controles ni límites a su arbitrio. La división de poderes, que se produce separando las (antes concentradas) atribuciones legislativa y federativa (en Locke) del poder ejecutivo, en tanto poderes independientes y autónomos, tiene como finalidad justamente la necesidad de crear poderes capaces de -con el poder necesario para-vigilar, controlar, limitar al poder político. Así que no puede decirse que el carácter absoluto del poder y su arbitrariedad no fueran el objeto del ataque liberal a la soberanía so pena de confundir el medio con el fin y corriendo el riesgo de no reconocer el lugar de la preocupación central de Locke y el liberalismo.

Con respecto a la afirmación del comentarista según la cual "la crítica liberal de la soberanía parte de la concepción horizontal de la formación del poder político", hay que señalar que el liberalismo (del que hay corrientes distintas) no tiene necesariamente una concepción horizontal de la formación del poder político. Lo que podemos encontrar como central o básico en el liberalismo es una elaboración lógico racional del poder político que los teóricos liberales elaboran para argumentar en favor del fundamento (no su formación) de dicho poder, esto es, el principio en el que descansa la afirmación y salvaguarda de los derechos individuales y colectivos.

Para lo que a la formación propiamente dicha del poder político respecta, el liberalismo - posterior al absolutismo- afirma la necesidad de controlar/ limitar el poder absoluto ya previamente existente. El poder para el liberalismo es un "mal necesario" al que hay que ponerle remedios. Con este fin su teoría ofrece una explicación lógico-racional de cómo fundamentar el poder en principios liberales. Pero ni siquiera esa defensa de los derechos individuales y colectivos implica una concepción horizontal (¿popular?) sino una afirmación de principios (que no son necesariamente "populares").

Más adelante el comentario de Humberto Schettino repropone esta misma idea - por lo que adelantamos esta breve referencia. Para el liberalismo (aunque no para Locke, pero éste no es el liberalismo) "soberano" es cada uno de los poderes en el ejercicio de sus funciones. Podemos hacer referencia al proceso de formación/afirmación del poder soberano y/o al proceso de aparición/afirmación del concepto respectivo que reconoce atribuciones jurídicas y políticas a ese poder, pero el "origen de la soberanía" no se da necesariamente "en el pueblo (horizontal)". La soberanía popular habla del pueblo como sujeto de la soberanía y en el que se funda el reconocimiento de la misma. Hablar de soberanía es hablar del reconocimiento jurídico y político 
del poder supremo (del cual el pueblo es - de nuevo-sujeto). Por ende lo que el liberalismo quiere "destruir" (como dice Schettino) es la unidad del poder pero no "de la soberanía", ya que sigue teniendo un sujeto unitario, si bien tres poderes que hacen uso de la soberanía en el ejercicio de sus funciones.

Las subsiguientes anotaciones van dirigidas por Schettino a la noción de Estado de derecho. Ésta, en efecto, "no es una característica privativa de los Estados liberales", desde el momento que "los Estados absolutos también establecen el imperio de la ley". Siendo cierto (y para seguir ilustrando, también hay un Estado democrático y un Estado social de derecho), hace falta decir que entienden cosas distintas por "derecho". A saber, el del absolutismo refiere a la voluntad soberana absoluta y al derecho a mandar del que detenta el poder, mientras que el del liberalismo refiere a los derechos inviolables de los individuos y la comunidad, así como a la sujeción a leyes por parte del mismo poder. También el fin que deben cumplir las leyes es consecuentemente diverso (pese a la coincidencia básica en la necesidad del orden).

Al hablar del Estado liberal (y por ende de ese Estado de derecho) tenemos ante nosotros un Estado limitado en sus poderes y funciones, por medio de su estructura tripartita de poderes, así como por la existencia de una constitución liberal y de leyes que le sujetan. De manera que el aspecto central de la crítica liberal a la soberanía (absoluta), sí proviene de la afirmación/defensa de la noción y realidad del Estado (liberal) de derecho y el imperio de la ley.

El siguiente tema que reúne varios señalamientos del comentarista es la "distinción entre república y democracia (que) no es clara" y atribuyo a estas tradiciones "diferentes versiones de la soberanía".

"La insatisfacción de los años sesentas con el individualismo", que Humberto Schettino menciona, no se relaciona con una noción genérica de libertad que no haga distingos entre "libertad (negativa o positiva)"; sino justo con una visión de la política que involucra la calidad de la participación ciudadana para que la práctica y defensa de las libertades civiles y políticas asuman aquel significado pleno y positivo que los republicanos quieren rescatar/reafirmar para la participación ciudadana e inyectar a las mismas instituciones políticas. Pese entonces a las sobreposiciones de significados entre democracia y república, el carácter distintivo del republicanismo reside claramente en una concepción virtuosa de la política (más precisamente de "la buena política", acepción que no interviene necesariamente en la caracterización de la democracia). Precisar en estas dos tradiciones la diferente manera de entender la relación entre derecho y poder parece justamente una buena manera de apreciar diferencias que de otra manera pueden pasar desapercibidas e identificar las dos con la democracia.

Con la intención inicial de distinguir república y democracia, Humberto presenta una distinción entre democracia antigua y moderna, partiendo im- 
plícitamente de la postura según la cual entre la democracia de los antiguos y de los modernos no hay más diferencia que el recurso necesario al medio de la representación ante la imposibilidad del ejercicio directo de la participación democrática. La famosa polémica en torno a tal cuestión (democracia de los antiguos y los modernos ¿son lo mismo?, ¿son distintas?, ¿lo son en lo esencial?, ¿parten de las mismas concepciones del hombre, de la política, de los fines de ésta?, etcétera) contribuyó a introducir muchas líneas problemáticas al respecto que no son de tan sencilla solución usando un criterio cuantitativo. Este momento del comentario encierra una mayor dificultad debido a la asunción de que en la democracia antigua y moderna se habla igualmente de soberanía. El gobierno del demos clásico y la democracia moderna no comparten la misma noción (ni realidad) de lo que es el "pueblo" ni "política" y, con ello, de "democracia" (más allá de la definición de democracia como "gobierno del pueblo"); pero, sobre todo, la soberanía del pueblo en cuestión, vinculada a la tradición jurídico-política moderna, propia del derecho constitucional e internacional, se encuentra necesariamente ligada a la experiencia del Estado moderno y a los resultados históricos, políticos, jurídicos, institucionales y culturales de esa particular estructura de poder.

Avanzando en la lectura del comentario, diremos que Tocqueville "no puede definirse más que como un liberal demócrata” sólo si hacemos caso omiso de la enorme complejidad y facetas de su pensamiento y postura políticos (siendo un autor que ha recibido múltiples caracterizaciones disímbolas: de aristócrata a democrático, pasando por conservador, liberal y republicano). Y en lo que respecta a su veta comprobada republicana de nuestro interés, lo que de su postura ayuda a precisar el acercamiento republicano no es la defensa de la libertad negativa (liberal), individualista y que se define en oposición al poder político - como afirma Humberto Schettino-, sino un ejercicio participativo y compositivo, "positivo" justamente propio de la novedosa dinámica de la democracia estadounidense y sus orgullosas asociaciones de ciudadanos; experiencias que tanto admiraron e inspiraron a Tocqueville (no sin tensiones y complicaciones) para pensar la posible salida a los movimientos revolucionario-populares de su tiempo. Por lo anterior, la defensa ante y contra la tiranía de las mayorías no es como entiende Schettino una defensa de la libertad negativa sino una reivindicación (enteramente republicana) de la buena política (la política de las virtudes políticas por excelencia).

La idealización del mundo político del mundo antiguo es sin duda uno de los límites del análisis de Hannah Arendt, pero de ello no se desprende que su postura no sea republicana, ya que presenta las características señaladas propias del republicanismo. Por otra parte, las reconstrucciones opuestas del republicanismo de Pocock o Putnam mencionadas por Schettino para oponerlas a la de Arendt se refieren al republicanismo renacentista que tenía 
-también- como nota central, la reivindicación del gran espíritu clásico de la polis griega y la res publica latina frente a la decadencia de la política de sus tiempos y a favor -nuevamente- de la buena política (no el poder del pueblo, visto más bien como vulgo).

Lejos del escepticismo ciertamente, la conclusión del artículo presentó varias líneas tanto políticas como teóricas sobre las que parece posible y deseable pensar la reformulación de la soberanía. Para ello -reiterando el objetivo del artículo- el análisis del significado complejo que las diferentes articulaciones de derecho y poder han dado a la soberanía puede contribuir a precisar la densidad y pluralidad de significados (rescatables y críticos) encerrados en ella.

La aparición de los diversos significados de soberanía a partir de esos distintos entretejimientos de la relación entre poder y derecho, a veces coexistentes, a veces en tensión, a veces implícitamente mezclados es los que hace imposible definir una postura unívoca y tomar una decisión tan simple como eliminar/abandonar o mantener la noción de soberanía. Dicha tarea es más bien complicada porque tiene ante sí la necesidad de rescatar, seleccionar, recuperar lo que de la soberanía es oportuno y deseable, en cuanto producto de afirmaciones históricas de tradiciones diversas que fueron definiendo nuestro mundo moderno. Ello implica la necesidad de tener que y saber definir qué es lo oportuno y rescatable de tan controvertido concepto. Y pensar la redefinición de la relación poder y derecho puede ayudar a plantear la cuestión de reformular la noción de soberanía para nuestros días.

Desde el análisis filosófico político la aportación posible es la del esclarecimiento progresivo de las temáticas y el señalamiento de problemas. Con la ayuda de otras disciplinas como la filosofía y la teoría jurídica, la sociología, así como de la confrontación con el mundo de la política y sus responsables, se podrá sin duda avanzar en propuestas acabadas y concretas. 